\title{
CURSOS SUPERIORES DE TECNOLOGIA: A MATERIALIDADE DA FORMAÇÃO ENXUTA E FLEXÍVEL PARA O PRECARIADO NO BRASIL ${ }^{1}$
}

\begin{abstract}
José dos Santos Souza²
Resumo

O artigo explicita a natureza dos Cursos Superiores de Tecnologia (CSTs) no Brasil. Com base em fontes primárias e secundárias, a análise aponta estreita relação entre estratégias de combate ao desemprego e reformas na política de educação profissional e tecnológica do país. Esta relação é mais explicativa da implantação dos CSTs do que o discurso governamental de oferta de formação mais focada e especializada. Para além de formar tecnólogos, estes cursos exercem papel importante na naturalização da instabilidade e vulnerabilidade do mercado de trabalho.
\end{abstract}

Palavras-Chave: Ensino Superior. Educação Tecnológica. Educação Profissional.

\section{CURSOS SUPERIORES DE TECNOLOGÍA: LA MATERIALIDAD DE LA FORMACIÓN AJUSTADA Y FLEXIBLE PARA EL PRECARIADO EN BRASIL.}

\section{Resumen}

Este artículo explica la naturaleza de los cursos superiores de tecnología (THC) en Brasil. Basado en fuentes primarias y secundarias, el análisis señala una estrecha relación entre las estrategias para combatir el desempleo y las reformas en la política de educación vocacional y tecnológica del país. Esta relación es más explicativa de la implementación de THC que el discurso del gobierno de ofrecer una capacitación más centrada y especializada. Más allá de la capacitación de tecnólogos, estos cursos juegan un papel importante en la naturalización de la inestabilidad y vulnerabilidad del mercado laboral.

Palabras clave: Educación superior. Educación tecnológica. Educación profesional.

\section{TECHNOLOGY HIGHER COURSES: THE MATERIALITY OF LEAN AND FLEXIBLE TRAINING FOR THE PRECARIAT IN BRAZIL.}

\section{Abstract}

This article explains the nature of Technology Higher Courses (THCs) in Brazil. Based on primary and secondary sources, the analysis points out close relationship between strategies to combat unemployment and the reforms in the country's vocational and technological education policy. This relationship is more explanatory of the implementation of THCs than the government speech of offer more focused and specialized training. Beyond to training technologists, these courses play important role in naturalization of instability and vulnerability of the labor market.

Keywords: Higher Education. Technological education. Professional education.

\footnotetext{
1 Artigo recebido em 29/11/2019. Primeira avaliação 18/02/2020. Segunda avaliação 14/02/2020. Terceira avaliação 10/03/2020. Aprovado em 27/04/2020. Publicado em 22/05/2020.

DOI: https://doi.org/10.22409/tn.v18i36.38855

2 Doutor em Sociologia pelo Instituto de Filosofia e Ciências Humanas da Universidade Estadual de Campinas (UNICAMP), São Paulo - Brasil, com Pós-Doutorado em Educação pela Faculdade de Educação da UNICAMP. Atua como professor de economia política da educação e de política educacional do Departamento de Educação e Sociedade do Instituto Multidisciplinar da Universidade Federal Rural do Rio de Janeiro (UFRRJ) - Brasil, onde integra o quadro docente do Programa de PósGraduação em Educação, Contextos Contemporâneos e Demandas Populares (PPGEduc). Coordenador do Curso de Especialização Lato Sensu em Gestão Educacional. Líder do Grupo de Pesquisas Sobre Trabalho, Política e Sociedade. Editor-Gerente da Revista Trabalho, Política e Sociedade (RTPS) - Brasil. E-mail:jsantos@ufrrj.br ORCID: 0000-0001-5433-0812
} 


\section{Introdução}

As transformações vivenciadas desde o final do século XX materializam a recomposição burguesa diante da crise orgânica do modelo de desenvolvimento do capital que tinha no taylorismo/fordismo seu regime de acumulação e no Estado de Bem-Estar Social seu modo de regulação social. A despeito do avanço da ciência e da tecnologia, bem como do processo civilizatório, essa recomposição burguesa tem intensificado ainda mais a precariedade do trabalho e da vida humana, caracterizando-se talvez como a mais perversa ofensiva do capital contra a classe trabalhadora. No Brasil, assim como em boa parte do mundo capitalista, esta conjuntura traz como principais consequências: o desemprego estrutural; o combate à livre organização coletiva dos trabalhadores; a desregulamentação dos direitos trabalhistas; a terceirização, a instituição do banco de horas, a regulamentação do trabalho intermitente; a proliferação do trabalho informal, do trabalho part-time, do trabalho em domicílio ou do que alguns teóricos vêm chamando de "uberização" do trabalho (SLEE, 2017). ${ }^{3}$

Além de ampla reestruturação produtiva, faz parte da recomposição burguesa a reorientação do papel do Estado e de sua relação com a sociedade. É deste contexto que emanam mudanças substantivas na política pública de formação humana. Uma destas mudanças consiste na flexibilização do trabalho pedagógico ${ }^{4}$ na formação de técnicos especializados ou tecnólogos para conduzir a operacionalidade da produção de bens e serviços na perspectiva da produção enxuta no regime de acumulação flexível do capital, com base em princípios do modelo japonês de produção.

\footnotetext{
${ }^{3}$ Aquilo que no Brasil e no mundo tem se propagado como "uberização" - termo derivado da forma de organização da empresa Uber - é uma nova configuração da exploração do trabalho e da apropriação das cidades a que Slee (2017) tratou como um aspecto de Economia do Compartilhamento (Sharing Economy). Este aspecto consiste em relações que antes, no cotidiano se davam diretamente entre trabalhadores e consumidores, mas que agora são mediadas por um novo parceiro, o aplicativo de smartphone que permite considerável ampliação da escala de negociação entre as partes originais. $\mathrm{Na}$ condição de elemento novo nesta relação, o aplicativo substitui os laços de confiança por avaliações e ostensiva vigilância externa, de modo que parte significativa do dinheiro envolvido nessas trocas é retida por ele. Este arranjo produtivo foi inicialmente propagado como meio de incentivar a solidariedade, o consumo sustentável e o compartilhamento de tecnologia, mas hoje ele se revela como uma tendência de novos negócios de natureza monopolista/oligopolista, com tendência a liquidar concorrentes, a ampliar a exploração do trabalhador e a estabelecer novas condições de precariedade do trabalho camufladas em uma relação supostamente colaborativa. Muitos autores, a exemplo de Franco e Ferraz (2019) e de Lima e Bridi (2019), têm ressaltado a intensificação da precariedade do trabalho como consequência da uberização.

4 Esta flexibilização do trabalho pedagógico adquire inúmeras características que vão desde a contratação temporária, até a uberização do trabalho docente, como nos revela Venco (2019).
} 
Tendo como referência este contexto sócio-histórico, nossa análise toma como objeto os Cursos Superiores de Tecnologia (CSTs), originários do interesse empresarial por formação de nível superior enxuta, flexível e permeável às variações do mundo da produção, de modo a formar um novo tipo de trabalhador especializado que transite entre o perfil do cientista e o perfil do técnico operacional, em nível intermediário, embora mais bem preparado para atender de forma imediata às demandas das empresas, de modo a contribuir para sua produtividade e competitividade no mercado globalizado. $O$ objetivo deste trabalho é explicitar a natureza dos CSTs no Brasil a partir de seus pressupostos sócio-históricos e políticos e ideológicos, tomando como referência empírica a divisão do trabalho educacional na Educação Superior do país, amparando-se em fontes bibliográficas primárias e secundárias.

O eixo central da análise consiste na estreita relação entre as estratégias de combate ao desemprego, às demandas objetivas de produtividade e competitividade das empresas reestruturadas e sua necessidade de garantir flexibilidade do trabalho e das relações de produção e as mudanças na política de educação profissional e tecnológica do país. É a partir das contradições que emanam dessa relação que buscamos compreender a origem e desenvolvimento dos CSTs, em busca de identificar a sua natureza. Assim pretendemos demonstrar neste texto que o fato de 0 desenvolvimento dos CSTs se dar majoritariamente em Instituições de Ensino Superior (IES) privadas, tendo como principais referências norteadoras de sua estruturação as ideologias da empregabilidade, do empreendedorismo e da sustentabilidade, articuladas aos princípios de flexibilidade e de produção enxuta, reforça ainda mais suas afinidades com a lógica mercantil e sua perspectiva pragmática, imediatista e interessada de formação humana, instituindo-se em uma espécie de formação enxuta e flexível cujo público-alvo privilegiado é o precariado.

O que compreendemos por precariado, a propósito, não se trata de uma nova classe social, conforme a perspectiva de Standing (2011). Na realidade, Braga (2012) nos alertou nesse sentido, quando indicou o precariado como a forma de ser do proletariado da era digital. Entretanto, conforme observa Alves (2018), o precariado não seria a forma de ser de todo o conjunto do proletariado, mas um segmento específico dele nascido na era digital que, embora faça parte da classe proletária, assume características próprias, tais como: alta escolarização e inserção instável e 
precária no mundo do trabalho. Para Alves (2013, texto em html), portanto, o precariado é:

a camada média do proletariado urbano precarizado, constituída por jovens-adultos altamente escolarizados com inserção precária nas relações de trabalho e vida social, [...] constituído, por exemplo, por um conjunto de categorias sociais imersas na condição de proletariedade como, por exemplo, jovens empregados do novo (e precário) mundo do trabalho no Brasil, jovens empregados ou operários altamente escolarizados, principalmente no setor de serviços e comércio, precarizados nas suas condições de vida e trabalho, frustrados em suas expectativas profissionais; ou ainda os jovens-adultos recém-graduados desempregados ou inseridos em relações de emprego precário; ou mesmo estudantes de nível superior $[\ldots]$.

Esta concepção de precariado trazida por Alves é a que norteia a nossa análise. Como Alves, portanto, entendemos o precariado como um segmento da classe trabalhadora composto por sujeitos que, apesar de terem concluído os níveis de escolaridade básica e correspondido aos apelos de auto investimento em formação profissional, sejam empregados ou não, conservam entre si uma característica comum: a condição precária de trabalho e de vida em sociedade. Nossa opção teórica pelo conceito de precariado na perspectiva de Alves (2013) se justifica por ser este o segmento que a maior parte dos CSTs, implícita ou explicitamente, tem como públicoalvo, conforme temos percebido a partir do monitoramento da propaganda feita pelas cinco IES que mais ofertam vagas para este grau acadêmico.

A análise se pauta na premissa de que esta relação entre a origem e o desenvolvimento dos CSTs e a lógica mercantil é muito mais explicativa da natureza desses cursos do que o discurso corrente de que eles são uma alternativa de formação mais rápida e mais focada, com foco na empregabilidade, no empreendedorismo e na sustentabilidade. Procuraremos neste texto apontar evidências de que os CSTs se inserem numa categoria de formação superior enxuta e flexível para o precariado, em um contexto marcado por volatilidade, incerteza, complexidade e ambiguidade, no campo ético e moral, e por desemprego e intensificação da precariedade do trabalho, no campo das necessidades materiais da vida. Afinal, para além de formar tecnólogos, a maior parte destes cursos tem cumprido papel importante na conformação ética e moral de parcela significativa da força de trabalho, de modo a educá-la para encarar com naturalidade as instabilidades e vulnerabilidades do mercado de trabalho em tempo de crise orgânica do capital. 


\section{Origem e desenvolvimento dos Cursos Superiores de Tecnologia no Brasil}

Conforme já assinalado em trabalhos anteriores (SOUZA, 2016; SOUZA e VEIGA, 2020), os CSTs são um tipo de graduação de curta duração, com carga horária mínima de 1.600 a 2.400 horas, dependendo da área, que se inserem na categoria de cursos de nível superior na área da educação profissional e tecnológica e conferem diploma de tecnólogo. Na condição de curso superior com características especiais, bem distintos dos tradicionais - embora o acesso se faça por meio de processo seletivo semelhante aos dos demais cursos de graduação -, os CSTs devem ser estruturados para atender aos diversos setores da economia, abrangendo áreas especializadas, tendo como foco o atendimento mais imediato de demandas do mercado. Segundo o Parecer CNE/CES n 436/2001 (BRASIL, 2001), os egressos desses cursos devem estar aptos a desenvolver atividades em determinada área profissional e devem ter formação específica para: a) aplicação, desenvolvimento, pesquisa aplicada e inovação tecnológica, bem como difusão de tecnologias; b) gestão de processos de produção de bens e serviços; e c) desenvolvimento da capacidade empreendedora (BRASIL, 2001, p. 09). Observe-se que os portadores de diploma de tecnólogo gozam de todas as prerrogativas legais que qualquer outro graduado em nível superior, podendo ter acesso a cursos de pós-graduação lato sensu e/ou stricto sensu em nível de mestrado e doutorado profissional ou acadêmico (Cf.: BRASIL, 2001).

A justificativa recorrente para criação de CSTs se baseia em dois argumentos principais. Um é o da necessidade de cursos superiores com duração mais reduzida para atender a supostos interesses da juventude em dispor de credencial para o mercado de trabalho - argumento da empregabilidade - em tempo mais reduzido; outro é o de que esse tipo de curso supostamente permitiria maior rapidez no atendimento a mutações do mercado, ao mesmo tempo em que permitiria maior aprofundamento em áreas profissionais específicas, em sintonia com o mundo do trabalho. O Parecer CNE/CES no 436/2001 é bastante enfático na crença de que estas características de permanente ligação com o meio produtivo e com supostas necessidades da sociedade "colocam esses cursos em uma excelente perspectiva de atualização, renovação e autorreestruturação, características também inerentes aos 
cursos sequenciais, porém cada vez mais presentes nos cursos de graduação" (BRASIL, 2001, p. 10).

Os CSTs atualmente existentes têm sua base legal originada no extinto Decreto no 2.208/1997 (BRASIL, 1997, Art. 3º), o qual havia estabelecido três níveis para a educação profissional: o básico, o técnico e o tecnológico. Este último correspondia a cursos de nível superior na área tecnológica que deveriam conferir diploma de tecnólogo. O Decreto n 5.154/2004 (BRASIL, 2004), ao revogar o Decreto ํo 2.208/1997, embora mantenha esses mesmos níveis da educação profissional, dáIhes nova denominação: ao nível básico, denomina de "qualificação profissional, inclusive formação inicial e continuada de trabalhadores”; ao nível técnico, denomina "educação profissional técnica de nível médio"; e ao nível tecnológico, denomina "educação profissional tecnológica de graduação e de pós-graduação". Este último corresponde aos CSTs e aos mestrados profissionais. Como se percebe, no que concerne à educação profissional tecnológica, o Decreto nํ 5.154/2004 só aprofunda o que o Decreto n 2.208/1997 havia estabelecido, ao tornar a nomenclatura mais claramente afinada com os interesses de mercado e ao estender a educação profissional e tecnológica até à pós-graduação - algo que não estava explícito no Decreto ํㅜ 2.208/1997. ${ }^{5}$

Mas a ideia de implementação de cursos superiores de curta duração com foco nas demandas imediatas do mercado não é uma iniciativa inédita. No início dos anos 1960, o Art. 104 da Lei nº 4.024/1961 (BRASIL, 1961) já abria a possibilidade de organização de cursos ou escolas experimentais, com currículos, métodos e períodos escolares próprios, o que se pode considerar como primeiro passo formal para a criação de cursos superiores diferenciados. Entretanto, segundo Brandão (2007, p. 03), foi a reforma universitária desencadeada pela Lei nํ⒌540/1968 (BRASIL, 1968,

\footnotetext{
${ }^{5}$ Em que pese a disputa política travada entre dois projetos distintos de formação humana no diálogo social promovido para a construção das bases do Decreto no 5.154/2004 - um de perspectiva de formação humana unitária e omnilateral, encabeçado pela Direção da SETEC/MEC à época inicial do Governo Lula, e outro de perspectiva pragmática, imediatista e interessada, encabeçado por lideranças empresariais -, a aposta na política conciliatória de interesses conflitantes fez com que o Decreto no $5.154 / 2004$ pouco avançasse em relação ao Decreto $n-2.208 / 1997$ por ele revogado. Talvez o saldo de maior relevo tenha sido o resgate do Ensino Médio integrado que havia sido extinto pelo Decreto revogado. Não obstante, o Decreto $n^{0}$ 5.154/2004 conserva a ideologia da empregabilidade como norteadora da política de educação profissional e tecnológica; mantém a pedagogia das competências como norteadora da perspectiva teórica e metodológica do ensino e da aprendizagem; e, ainda, aperfeiçoa a iniciativa de possibilitar cursos superiores de carga horária reduzida, com estrutura curricular enxuta, com maior flexibilidade para atender a demandas imediatas do mercado, explicitando a extensão deste tipo de formação ao nível de pós-graduação.
} 
Art. 18) que deflagrou diversos dispositivos legais, tanto no âmbito federal quanto no âmbito de diversos estados da federação, no sentido de difundir e implantar cursos superiores de curta duração destinados a proporcionar habilitações profissionais intermediárias, mais afinadas com as demandas do mercado. Tais iniciativas tiveram alguma resistência por parte de segmentos universitários, embora bastante limitadas pelas características de um contexto de ditadura militar.

Brandão (2007, p. 04) aponta que, já na primeira metade dos anos 1960 havia propostas governamentais de implantação de cursos superiores diferentes dos tradicionais e que, em 1962, o Conselho Federal de Educação respaldou uma proposta de criação de uma modalidade distinta de formação de engenheiros para atender especialmente à indústria automobilística. Tratava-se do Curso de Engenharia de Operação, definido como um tipo de formação profissional tecnológica de nível superior com duração de 3 anos.

Durante a década de 1970, esses cursos tiveram grande dificuldade de se afirmarem, em função da resistência das associações de classe dos engenheiros que repudiavam o fato de um profissional formado em curta duração ser chamado de "engenheiro". É somente em 1977 que esta polêmica foi dirimida com a extinção do Curso de Engenharia de Operação e a criação de uma nova modalidade de curso de engenharia, o Curso de Engenharia Industrial, com duração de 5 anos, considerado aceitável para formar engenheiros (BRANDÃO, 2007, p. 07). Apesar de resistências em relação ao título profissional, prevalecia a ideia de necessidade de formação de um profissional mais especializado em uma faixa menor de atividades, com currículo mais enxuto, de modo a formar um trabalhador com flexibilidade suficiente para dar respostas mais imediatas a problemas práticos do dia-a-dia da produção. Nessa perspectiva, em 1978, foram então criados três Centros Federais de Educação Tecnológica (CEFETs) que, dentre outras atribuições, cabia-lhes a tarefa de formar, em nível superior, profissionais em engenharia industrial (em 5 anos) e tecnólogos (em curta duração). O fato é que, a partir de 1972, observa-se no Ministério da Educação (MEC) o início de uma política clara de incentivo a cursos superiores de curta duração, não somente na área de engenharia, mas em praticamente todos os setores da economia (NASCIMENTO, 1987 apud BRANDÃO, 2007, p. 7). Segundo Brandão (2007, p. 07), "a partir de então ocorre o verdadeiro impulso para os cursos superiores de curta duração a nível nacional [sic]". 
Como exemplo de ação governamental para implantação de cursos superiores de curta duração para formar tecnólogos, podemos apontar o que ocorreu em São Paulo, em 1968, quando o governo estadual acionou seu Conselho Estadual de Educação para pronunciar-se a respeito da possibilidade de implantação de cursos de curta duração para formar uma nova modalidade de profissionais. Este episódio resultou na criação do Centro Estadual de Educação Tecnológica Paula Souza (CEET-PS) que, a partir de 1970, manteve a oferta de cursos técnicos de nível superior. A partir de 1973, o CEET-SP passou a ser instituição mantenedora de diversas Faculdades Tecnológicas Estaduais, por meio das quais passou a organizar seus cursos técnicos de nível superior até meados dos anos 1990, quando os CSTs foram instituídos em nível nacional pela reforma da Educação Profissional desencadeada a partir de 1997, pelo Governo Fernando Henrique Cardoso (FHC).

A consolidação definitiva da proposta de cursos superiores de duração reduzida para formar tecnólogos, sem dúvida, ocorreu a partir do Governo FHC, especialmente por intermédio da ampliação de vagas para esse tipo de curso na iniciativa privada, referendadas pelo Conselho Nacional de Educação (CNE), que regulamentou a estrutura e o funcionamento dos CSTs a partir do Decreto no 2.208/1997 (BRASIL, 1997). Não obstante, é durante o Governo Lula da Silva que a oferta desses cursos se estende para praticamente toda a Rede Federal de Educação Profissional, Científica e Tecnológica, em decorrência do Decreto no 5.154/2004 e da Lei no 11.892/2008 (BRASIL, 2004; 2008), e mantém sua franca expansão na iniciativa privada. Veja o gráfico, a seguir:

\section{Gráfico 1 - Série histórica do número de CST, por categoria administrativa - 2002 a 2018.}

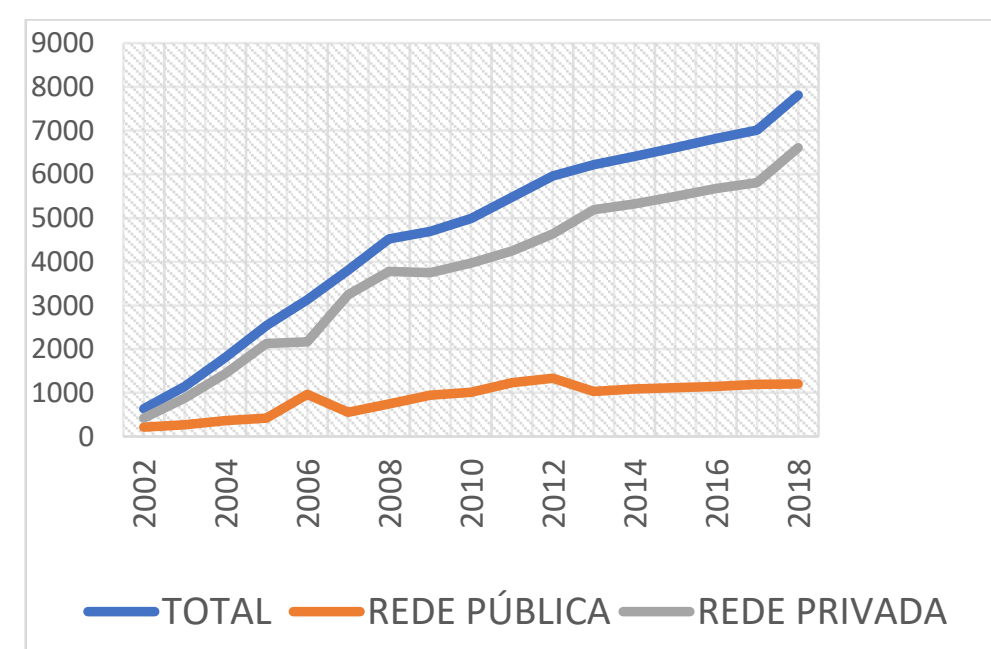

Fonte: Veiga (2020, p. 288) 
Ao final dos anos 2000, os CSTs passaram a ser uma realidade consolidada, tanto nas redes públicas de ensino - em especial na rede federal e nas redes estaduais de ensino profissional e tecnológico - quanto na rede privada. Se bem que são as IES privadas as que mais têm investido na implantação deste grau acadêmico, com oferta de cursos nas mais variadas área do setor produtivo de bens e de serviços, sejam eles na modalidade presencial, semipresencial ou à distância.

Hoje, os CSTs representam $20,6 \%$ do total de quase 38 mil cursos superiores ofertados em todo o país e 13\% do total de pouco mais de 8,4 milhões de matrículas no Ensino Superior. Todavia, como é possível constatar nas Tabelas 01 e 02, a maior parte dos CSTs e das respectivas matrículas pertencem a IES privadas. Esta categoria administrativa é responsável por $84,5 \%$ do total de pouco mais de 7,8 mil CSTs e por $84,7 \%$ do total de quase 1,1 milhão de matrículas nesses cursos. Ao que tudo indica, os CSTs se tornaram um atrativo filão do mercado educacional, especialmente após a política de expansão do Ensino Superior promovida pelo Governo Federal a partir de 2002.

Tabela 01: № de Cursos de Graduação - Presenciais e a Distância, por Grau Acadêmico (Bacharelado, Licenciatura, Tecnólogo), segundo a Categoria Administrativa das IES - 2018

\begin{tabular}{ccccc}
\hline Cursos / Categoria & \multicolumn{4}{c}{ Cursos de Graduação } \\
\cline { 2 - 5 } Administrativa & Total & Bacharelado & Licenciatura & Tecnólogo \\
\hline Número de Cursos & 37.962 & 22.737 & 7.415 & 7.810 \\
Pública & 10.526 & 5.528 & 3.785 & 1.213 \\
Federal & 6.503 & 3.689 & 2.130 & 684 \\
Estadual & 3.442 & 1.482 & 1.475 & 485 \\
Municipal & 581 & 357 & 180 & 44 \\
Privada & 27.436 & 17.209 & 3.630 & 6.597 \\
\hline
\end{tabular}

Fonte: MEC/INEP/DEED (INEP, 2019), elaboração própria.

Embora o número de matrículas em cursos de bacharelado no setor privado seja de longe maior que o número de matrículas em CSTs e em cursos de licenciatura, é possível constatar que o número de cursos nesses dois últimos graus acadêmicos é bem próximo, conforme se constata na Tabela 01. 
Tabela 02: № de Cursos de matrículas em Cursos de Graduação -

Presenciais e a Distância, por Grau Acadêmico (Bacharelado, Licenciatura, Tecnólogo), segundo a Categoria Administrativa das IES - 2018

\begin{tabular}{crrrrr}
\hline Matrículas / & \multicolumn{5}{c}{ Matrículas em Cursos de Graduação } \\
\cline { 2 - 6 } Administrativa & Total & Bacharelado & Licenciatura & Tecnólogo & $\begin{array}{c}\text { Não } \\
\text { Aplicável }\end{array}$ \\
\cline { 2 - 6 } Matrículas & 8.450 .755 & 5.689 .335 & 1.628 .676 & 1.098 .066 & 34.678 \\
Pública & 2.077 .481 & 1.261 .979 & 612.427 & 168.526 & 34.549 \\
Federal & 1.324 .984 & 866.021 & 355.794 & 77.308 & 25.861 \\
Estadual & 660.854 & 322.194 & 241.222 & 88.750 & 8.688 \\
Municipal & 91.643 & 73.764 & 15.411 & 2.468 & - \\
Privada & 6.373 .274 & 4.427 .356 & 1.016 .249 & 929.540 & 129 \\
\hline
\end{tabular}

Fonte: MEC/INEP/DEED (INEP, 2019), elaboração própria.

Nota: "Não aplicável" corresponde à Área Básica de Cursos na qual não está definido o grau acadêmico.

Seria oportuno o registro da necessidade de se estabelecer comparações entre a renda familiar dos estudantes matriculados em IES privadas tanto em cursos de licenciatura quanto em CSTs, com aqueles matriculados em cursos de bacharelado. Tal comparação talvez nos permitisse verificar se existe alguma relação entre a faixa de renda e a escolha por determinado grau acadêmico nesta população. Entretanto, esta tarefa fugiria ao escopo deste trabalho. Deixemos esta tarefa para estudos posteriores e procuremos aqui nos ater somente à natureza dos CSTs no Brasil.

\section{Natureza dos Cursos Superiores de Tecnologia}

A pretexto de atender a demandas de produtividade e competitividade das empresas, de garantir empregabilidade aos trabalhadores, de acordo com as perspectivas da ideologia do empreendedorismo, na realidade, a política de expansão do Ensino Superior no Brasil trouxe em seu bojo a propagação dos CSTs como alternativa de acesso a esse nível de ensino para amplo segmento da classe trabalhadora que há algum tempo almejava este nível acadêmico. Sem êxito na tentativa de ingressar em IES públicas e sem recursos para arcar com custos de um curso em uma IES privada, muitos jovens trabalhadores passaram a contar não só com o Programa de Apoio a Planos de Reestruturação e Expansão das Universidades Federais (REUNI), mas também com o Programa Universidade para Todos (PROUNI) e com o Novo Fundo de Financiamento Estudantil (FIES). Estas iniciativas 
governamentais abriram as portas do Ensino Superior para muitos, especialmente nas IES privadas, considerando-se que a expansão do Ensino Superior foi bem mais significativa no setor privado do que no público e bem mais em cursos de licenciatura e em CSTs do quem em bacharelados. Em um estudo recente sobre as determinações sócio-históricas das mudanças recentes na gestão da educação profissional tecnológica no Brasil, acerca da expansão do número de CSTs e de respectivas matrículas, Veiga (2020, p. 290) afirma:

Notamos que o fomento aos CST que impulsionou o aumento no número de cursos, [...] também incidiu no número de matrículas. Entre 2010 e 2018, o número de matrículas nos CST aumentou cerca de $40 \%$, contudo, isso não se expressou em todas as categorias administrativas. [...] As IES públicas federais tiveram $22 \%$ de aumento no número de matrículas, as IES públicas estaduais tiveram $81 \%$ de aumento e as IES privadas "com fins lucrativos" apresentaram o maior percentual de aumento nesse quesito: $97 \%$. Ao contrário disso, IES públicas municipais e IES privadas "sem" fins lucrativos apresentaram diminuição de $40 \%$ e $35 \%$, respectivamente, no número de matrículas em CST.

A expansão dos CSTs também apresenta peculiaridades no que se refere à modalidade de ensino, o que vem se configurando como uma tendência. Trata-se do crescimento significativo da oferta desses cursos na modalidade EaD:

\begin{abstract}
A tendência no número de matrículas nos CST também evidencia diferentes cenários por modalidade de ensino. O número de matrículas nos CST na modalidade presencial apresentou retração de 3\% no período de 2010 a 2018. Se considerarmos o período 2013 a 2018 esse percentual de retração aumenta para quase $20 \%$. Ao contrário disso, o número de matrículas nos CST na modalidade EaD apresentou aumento de $141 \%$, ultrapassando o número de matrículas na modalidade presencial no ano de 2018 (VEIGA, 2020, p. 292).
\end{abstract}

Com a proliferação dos CSTs principalmente em IES privadas, a custo bem mais atraente do que cursos de bacharelado ou mesmo de licenciatura, muitos jovens trabalhadores viram neles a oportunidade de obter o diploma de nível superior e, assim, conquistar a tão propagada empregabilidade embalados por uma postura empreendedora, de acordo com os critérios de sustentabilidade. Por meio da análise de propagandas feitas por instituições públicas e privadas direcionadas a seu públicoalvo durante o período de 2018 e 2019, foi possível observar que as IES privadas, atentas a este filão do mercado, utilizaram-se da estratégias de propaganda e marketing que não distingue claramente os CSTs dos demais cursos superiores, 
fomentando a ideia de que se tornara possível concluir um curso superior em menos tempo e com menor investimento financeiro com projeto curricular mais pragmático, com foco no mercado. Quando alguma diferença entre os diversos graus acadêmicos é mencionada, é com o intuído de ressaltar a redução do tempo para se formar como uma vantagem. Sem contar que tanto o PROUNI quanto o Novo FIES serviram de alternativa de financiamento para tornar sonhos em realidade para boa parte do público-alvo dos CSTs. Assim, muito mais do que alternativa de formação em nível superior de quadros profissionais mais focados nas demandas do mercado, os CSTs se tornaram uma alternativa de conformação de amplo contingente de jovens trabalhadores das camadas mais pobres que, mobilizados pelas ideologias da empregabilidade, do empreendedorismo e da sustentabilidade, direcionam seus esforços em busca de ascensão social via melhor colocação no mercado de trabalho. Isto claramente é perceptível na estratégia de propaganda e marketing das IES privadas.

\section{Figura 1 - Propaganda de instituição privada de ensino superior no bairro de Madureira, Rio de Janeiro - 2019}

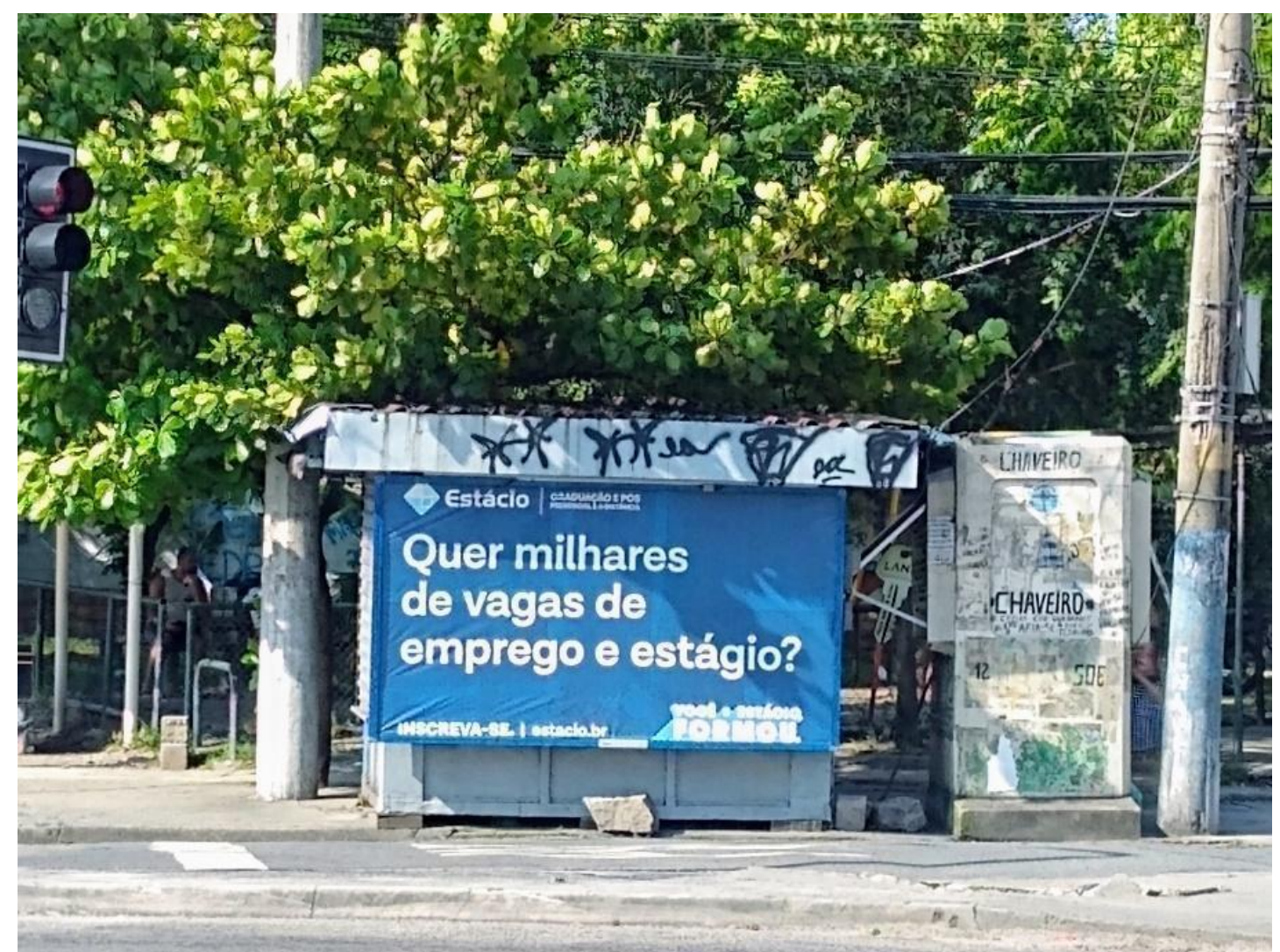

Fonte: Registro fotográfico do acervo pessoal do autor. 
Em que pese o fato de 7,1\% dos CSTs serem ofertados por instituições de ensino da Rede Federal de Educação Profissional, Científica e Tecnológica, com estrutura física e quadro docente hoje bastante similar ao das universidades federais, esta fração não expressa a realidade do universo de CSTs ofertados no país. Ainda que essa fração seja somada à oferta dos demais instituições públicas (universidades, centros universitários e faculdades federais, estaduais e municipais), não ultrapassará $15,5 \%$.

Outro aspecto da origem e desenvolvimento dos CSTs que delineiam sua natureza reside no fato de que sua materialidade ratifica a velha dualidade educacional em condições renovadas, agora estendida ao ensino superior. Para uns poucos, dispensa-se o ensino superior de alta qualidade em instituições públicas de ensino, não necessariamente gratuitas, mas com amplas possibilidades de desenvolvimento científico e tecnológico, ainda que limitado à pesquisa aplicada, numa perspectiva de formação humana interessada, voltada para o domínio técnico e operacional necessário para o exercício do trabalho complexo. Já para uma imensa maioria, resta o ensino superior enxuto e flexível, de caráter privado, majoritariamente na modalidade de EaD, focado na ideologia do empreendedorismo, da empregabilidade e da sustentabilidade, interessado exclusivamente na conformação ética e moral de amplo contingente de trabalhadores jovens mobilizados para o auto investimento em educação profissional.

Neste contexto, prevalece a perspectiva pragmática, imediatista e interessada de formação humana para o exercício do trabalho que se situa entre o trabalho simples e o trabalho complexo. Assim os CSTs estendem a dualidade para o Ensino Superior. Agora, além da licenciatura, os menos favorecidos contam também com a possibilidade de ingresso em CSTs que se situam exatamente entre o espaço de formação do Técnico e o de formação do cientista: trata-se do espaço de formação do tecnólogo. Configura-se, portanto, uma tendência em que os CSTs, junto com os cursos de licenciatura, são apresentados para o precariado como única possibilidade de acesso ao ensino superior, embora majoritariamente ofertados por IES privadas e na modalidade de EaD.

No que se refere à formação do tecnólogo, o caráter majoritariamente privado da oferta de cursos funciona como uma espécie de pedagogia política renovada para a construção do consenso em torno de determinado projeto político de formação humana no Brasil. No bojo dessa pedagogia política, constam conteúdos que buscam 
resgatar o consenso em torno da legitimidade da livre concorrência, revitalizando-a, na tentativa de estabelecer na sociedade civil o ambiente propício à livre competição entre os indivíduos. Esta pedagogia política se desenvolve por intermédio do apelo à individualidade, ao imediato, aos interesses locais. Constrói-se uma supervalorização à organização corporativa ou de outros tipos de arranjos produtivos locais. Às vezes, até na forma de organizações não-governamental, em parceria com o Estado, como forma de valorização do comportamento econômico-corporativo em detrimento da organização da sociedade em torno de interesses políticos de caráter coletivo. Nesta perspectiva o trabalhador é levado a enxergar a si próprio como uma empresa e a sua força de trabalho como um capital - o capital humano -, assumindo nas relações sociais de produção o papel de uma espécie de microempreendedor individual. ${ }^{6}$

Faz parte desta pedagogia política, também, a disseminação de formas pseudocientíficas de apreensão da realidade social que valorizam o particular, o local, o efêmero, em detrimento de uma compreensão mais objetiva dos elementos que articulam e dão sentido ao Bloco Histórico ${ }^{7}$ que comporta as diversas particularidades da vida social. Desse modo, o próprio critério de cientificidade é flexibilizado, conduzido a leituras superficiais da realidade, elucubrações ou mesmo narrativas da vida cotidiana baseadas em olhares cada vez mais particulares, fundamentados em absoluto relativismo. À propósito, o próprio relativismo e erigido à condição de argumento metodológico e seu resultado é conduzido ao status de ciência, ou seja, o relativismo assume o caráter de critério de cientificidade.

A partir dessa banalização do fazer científico, ofuscam-se aspectos teóricos e metodológicos de interpretação do fenômeno social, concebendo o pensamento social como mera narrativa especulativa, desprovida de qualquer compromisso de apreensão das contradições que comportam sua concreticidade, sua complexidade.

\footnotetext{
${ }^{6}$ Tem sido muito difícil acessar os projetos pedagógicos dos cursos ofertados pelas IES investigadas. Mas esta tendência é perceptível no material descritivo destes cursos disponibilizados aos candidatos a ingresso que normalmente é disponibilizado nos sites das IES investigadas.

7 Bloco Histórico consiste em uma unidade contraditória e discordante entre o econômico e o político, entre a natureza e o espírito. Trata-se, em um sentido dialético, da unidade dos contrários e dos distintos. Gramsci chamou de bloco histórico o estágio em que a relação entre governantes e governados, mediatizada pelos intelectuais, se estabelece, graças a uma ação orgânica, possibilitada pela hegemonia, propiciando a troca de elementos individuais entre governantes e governados, entre dirigentes e dirigidos, consolidando-se, assim, o sentimento de unidade entre intelectuais e massa, entre filosofia e senso comum, de onde emana a vida do conjunto (GRAMSCI, 1999 e 2000a; PORTELLI, 1997). Faz parte dessa unidade a conformação de determinados regimes de acumulação de capital a um determinado modo de regulação social, ou seja, a unidade contraditória entre estrutura e superestrutura.
} 
Invariavelmente, esse método analítico - ou negação da própria ideia de método abstém-se de qualquer consideração da totalidade em que o objeto de análise se insere, de modo a atribuir a seu caráter particular, a sua especificidade, absoluto potencial explicativo da realidade, sem qualquer preocupação com as relações que este objeto comporta entre si e outros elementos da realidade social. Ao contrário do que Kosik (2010) aponta como dialética do concreto, nessa perspectiva analítica, o conhecimento social se estabelece a partir de sua manifestação fenomênica, onde o olhar particular, desprovido de critério distinto do interesse individual do pesquisador, concebe como "concreto" o que não passa de apreensões imediatas e particulares de determinado objeto, naturalizando determinado fenômeno social em si como uma realidade irrefutável, uma espécie de representação social, uma vez que foi assim percebida pelo seu pensador em de terminado contexto sócio-histórico.

Nessa perspectiva analítica da nova pedagogia política do capital, a naturalização da ideologia da "mão invisível do mercado" como reguladora eficiente do cotidiano social se apresenta como uma realidade naturalizada, de modo que qualquer especulação que the atribua relações com outros elementos da realidade, como por exemplo, a precarização do trabalho, é imediatamente rechaçada. De modo geral, esta pedagogia política constitui o mecanismo pelo qual o Bloco no Poder ${ }^{8}$ aciona políticas públicas para formar as competências necessárias não só para a conformação psicofísica, mas também para a conformação ético e moral dos trabalhadores. Este mecanismo obedece a uma dinâmica renovada de construção do consenso em torno da concepção de mundo burguesa, consolidando-se, assim, no meio social, por intermédio da naturalização da lógica de mercado, não só como elemento unificador da burguesia, mas também como pedagogia política para educar a sociedade civil para o consenso em torno dessa lógica, com vistas na subsunção real do trabalho ao capital.

\footnotetext{
8 Bloco no Poder é um conceito de Poulantzas (1977) para expressar a relação existente entre diferentes frações da classe dominante e o Estado. Trata-se de uma unidade contraditória entre as diferentes frações da classe dominante em nome de seus interesses coletivos diante da luta entre as classes sociais. Esta unidade é protagonizada pelo Estado, que atua como instituição educadora da sociedade civil para o consenso, de modo a mediar o conflito de classes em nome dos interesses coletivos burgueses. Portanto, trata-se de uma unidade política, econômica e ideológica entre diferentes frações da burguesia como meio para manter sua dominação sobre a classe trabalhadora (BERRINGER, 2015, p. 10).
} 
Como se pode observar na Imagem 2, esta perspectiva é naturalizada já no material informativo acerca dos cursos ofertados. Observe-se que o discurso tem como foco a curta durabilidade do curso, o baixo custo e celeridade e o pragmatismo na formação de competências imediatas para o mercado. Este discurso é a tônica de todas as propagandas analisadas em cinco IES privadas que mais ofertam CSTs presenciais, semipresenciais e/ou à distância no país

\section{Figura 2 - Site de uma IES privada onde constam informações sobre CSTs ofertados - 2020}

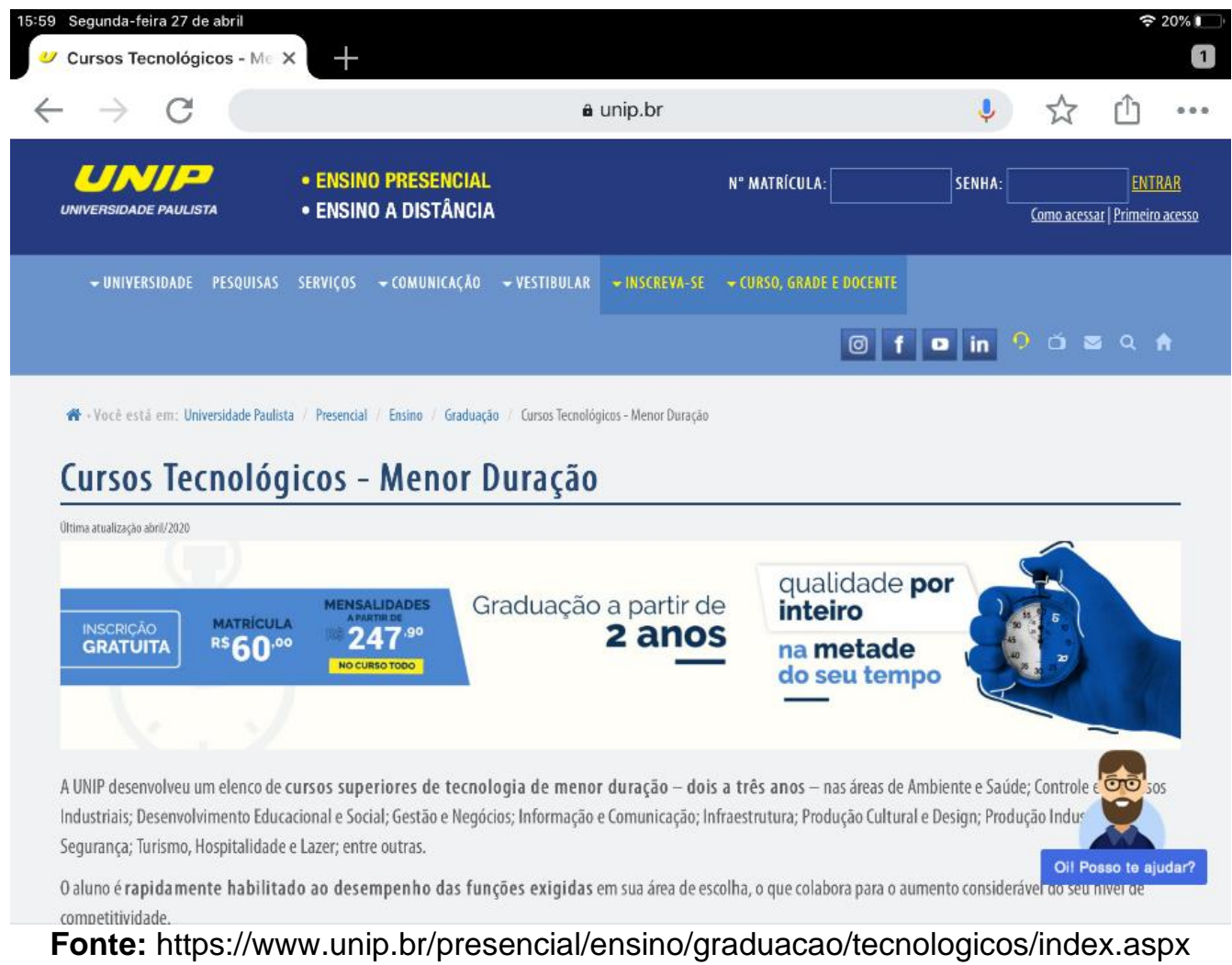

$\mathrm{Na}$ forma em que foram pensados, os CSTs são um espaço formativo em que a pedagogia política renovada do capital encontra campo fértil. Afinal, este grau acadêmico não se caracteriza somente pela redução do tempo de duração dos cursos, mas também pela redução considerável de seu conteúdo curricular, numa perspectiva interessada em selecionar apenas aqueles conteúdos que são considerados necessários para a formação de competências operacionais, configurando-se como uma espécie de socialização limitada do conhecimento científico e tecnológico a apenas o quê um determinado ramo produtivo exige do trabalhador para considerá-lo habilitado a desempenhar uma função especifica, nada mais além disto. 
De fato, a necessidade estrutural do estágio atual de desenvolvimento do capital de ampliar - mesmo que de forma ainda limitada - as oportunidades de acesso ao conhecimento para uma parcela restrita da classe trabalhadora, necessariamente, se justificam na sociedade civil por meio de um discurso integrador de defesa da universalização da Educação Básica, ampliação do acesso ao Ensino Superior e ampliação das oportunidades de Educação Profissional, inclusão social de jovens e combate ao trabalho infantil. Mas este discurso é, na realidade, uma ilusão necessária à manutenção do monopólio do conhecimento. Por meio desta ilusão, o Bloco no Poder controla o acesso ao conhecimento científico e tecnológico aplicado na produção, promovendo diferentes tipos de formação para diferentes segmentos da classe trabalhadora. É inerente a este fenômeno a ocorrência da dualidade entre formação para o trabalho complexo, de natureza científica - destinado a uma elite da classe trabalhadora - e formação para o trabalho simples - destinado à grande maioria dos trabalhadores. Eventualmente, o processo de produção de bens e serviços, a fim de ampliar suas taxas de mais-valia relativa por meio de maior qualificação do trabalhador (capital humano), recorrem a um nível intermediário de socialização do conhecimento científico e tecnológico que, conforme já mencionado, transita entre a formação do cientista e a formação do técnico, no caso o tecnólogo.

Esse contexto exige não só a formação enxuta e flexível de trabalhadores de novo tipo mais adaptados às novas demandas do mundo do trabalho, mas também a sua conformação ética e moral para assimilar com naturalidade a volatilidade, a incerteza, a complexidade e a ambiguidade do modelo flexível de desenvolvimento do capital marcado pela instabilidade e pela completa vulnerabilidade da vida dos trabalhadores. Nesse aspecto, a estruturação dos CSTs assume caráter estratégico importante, não só para alimentar as empresas com trabalhadores formados por um currículo enxuto e flexível, com postura empreendedora e conduta suficientemente competitiva, mas também para conformar o imenso contingente de trabalhadores excluídos do mercado formal para enfrentar com resiliência sua condição vulnerável e a ver com naturalidade a precariedade social do trabalho e da vida.

Dialeticamente, é exatamente na limitação da política pública de formação humana para cumprir seu propósito de socializar o conhecimento científico e tecnológico necessário para o trabalho e para a vida em sociedade, ainda que de modo fragmentado e numa perspectiva dualista, o que constitui o elemento positivo para a organização e luta dos trabalhadores contra o capital, contra o monopólio do 
conhecimento. ${ }^{9}$ Tal positividade consiste exatamente no fato de que essa limitação do capital, na medida em que se evidencia nas contradições de suas políticas públicas de formação humana, abre amplas possibilidades de mobilização da classe trabalhadora, ao mesmo tempo em que desmascara a pedagogia política renovada do capital para conformá-los na sua condição de trabalho e de vida precária.

Assim, devido à incapacidade do padrão compósito vigente para garantir emprego, seguridade social e inclusão social, já que sua preocupação é reorientar o uso do fundo público para garantir estabilidade financeira ao grande capital, o tipo de formação humana destinado aos filhos da classe trabalhadora ganha contornos ainda mais perversos, pois cabe-lhe também conformar ética e moralmente um número considerável de jovens e adultos fadados ao desemprego, à informalidade, ao contrato precário de trabalho (estágios, emprego temporário, trabalho intermitente etc.), condenados à condição de vulnerabilidade permanente - o precariado. Assim, a formação humana destinada a eles radicaliza cada vez mais sua função política de mediação do conflito de classes por meio da pedagogia política renovada do capital que visa naturalizar a intensificação da precariedade do trabalho e da vida no estágio atual do capitalismo. Para isto, aciona reformas curriculares que priorizam determinados conhecimentos fragmentados e determinados conteúdos que não passam de apologia à legitimação do desenvolvimento (in)sustentável, à competitividade mercantil, ao individualismo, ao empreendedorismo e à empregabilidade.

Nestes termos desenvolve-se a contrarreforma burguesa na Educação Profissional e Tecnológica para atender às novas demandas de formação/qualificação do trabalhador brasileiro. Em linhas gerais, ela pode ser definida como um conjunto de mudanças no planejamento e gestão educacional e nos processos pedagógicos que se estenderam desde o Governo FHC, passando pelo Governo Lula da Silva, tendo continuidade no Governo Dilma Rousseff, provocando mudanças substantivas no trabalho educativo realizado pelas IES. No decurso desta contrarreforma, fica

\footnotetext{
${ }_{9}^{9}$ Para a compreensão objetiva deste contexto, a teoria do Estado formulada por Gramsci $(1989 ; 2008)$ é providencial, na medida em que incorpora o conceito de hegemonia e amplia a concepção de Estado, concebendo-o como resultado da condensação de forças políticas em disputa na sociedade civil. De acordo com esse quadro analítico gramsciano, o aspecto dialético do desenvolvimento das políticas públicas de formação humana na ordem social burguesa de produção e reprodução social da vida material ganha mais clareza, a ponto de ver nelas alguma possibilidade de ação contra hegemônica, e nos permite enxergar elementos que, frequentemente, as análises acerca da ação pública no campo da formação humana não consideram.
} 
evidente o esforço do empresariado e do Estado para conferir ao trabalho pedagógico um caráter mais "interessado", preocupados em atender de forma mais imediata às demandas atuais de produtividade e competitividade das empresas.

Nessa perspectiva, a concepção da relação entre ciência e vida, entre trabalho e educação, entre empresa e escola que passa a predominar na gestão do trabalho escolar ganha caráter mais pragmático, mais de acordo com a lógica mercantil, mais coerente com os princípios neoliberais de competitividade como fator de qualidade, conforme as indicações de Friedman (1985) e de Mello (2005), dentre outros. Obviamente, essas ideias, na medida em que passam a dar direção à vida cotidiana das IES, provocam certo reordenamento dos princípios éticos e morais que norteiam seu trabalho acadêmico, dando novos significados às relações pedagógicas e políticas ocorridas em seu cotidiano, de modo a instituir certa mudança na cultura acadêmica, com o intuito de conservar, em condições renovadas, o potencial dessas instituições como espaço privilegiado de mediação do conflito de classes e de propagação do consenso em torno da concepção de mundo burguesa, ou seja, como aparelhos privados de hegemonia.

Nesse aspecto, a origem e desenvolvimento dos CSTs cumpre papel importante no processo de recomposição burguesa frente à crise orgânica do capital. Este grau acadêmico acaba por instituir o enxugamento curricular e a flexibilidade necessária para que a política de formação tecnológica possa cumprir de modo eficiente sua dupla função, seja para atender objetivamente as demandas do mercado, seja para conformar o precariado - amplo contingente de trabalhadores jovens fadados ao desemprego e à informalidade do trabalho - por meio dos princípios do empreendedorismo, da empregabilidade e da sustentabilidade.

\section{Conclusão}

Como demonstrado, o conjunto de IES privadas são predominantes no cenário da Educação superior do país, tanto no que se refere ao número de organizações acadêmicas quanto ao número de cursos de graduação e número de matrículas. Percebe-se que as IES privadas ainda centram seus esforços na oferta de cursos de bacharelado, embora não se abstenham de ofertar cursos de licenciatura e CSTs. Por outro lado, o conjunto de IES públicas está aquém de atender a demanda social por Educação Superior. Exemplo disto é que o número de Institutos Federais de 
Educação, Ciência e Tecnologia (IFs) e de Centros Federais de Educação Tecnológica (CEFETs) ainda é muito pequeno, pois juntos somam apenas 40 IES, o que representa $1,6 \%$ das 2.537 IES do país. Sua participação na oferta de CSTs é de $7,1 \%$ do total de 7.810 cursos deste grau acadêmico ofertados no país. Dos 1.213 CSTs ofertados por IES públicas, $45,6 \%$ são de responsabilidade dos IFs e CEFETs, enquanto as IES estaduais e municipais ficam responsáveis por $40 \%$ e 3,6\% respectivamente. Outros $10,8 \%$ são ofertados por outras IES federais distintas da Rede Federal de Educação Profissional, Científica e Tecnológica. Somado o número de matrículas em CSTs pertencentes aos IFs e CEFETs, constata-se que este também é tímido, pois não chega a 5,5\% do total de 1.098 .066 matrículas neste grau acadêmico.

Em caráter majoritariamente privado (84,5\%), a oferta de CSTs materializa aquilo que hoje o Ensino Superior brasileiro oferece como alternativa de formação enxuta e flexível que transita entre a formação do cientista e a do técnico, numa perspectiva pragmática, imediatista e interessada cujo foco é a formação em curto prazo de competências operacionais necessárias na produção de bens e serviços. Tal formação enxuta deve também formar nos trabalhadores a flexibilidade necessária para assimilar imediatamente eventuais mudanças e inovações em determinado processo produtivo. Neste aspecto, a implantação e propagação deste grau acadêmico como alternativa de Ensino Superior no país está longe de contribuir para a superação das desigualdades no acesso ao conhecimento científico e tecnológico aplicado na produção e ao desenvolvimento da Educação Profissional do país. Ao contrário, as aprofunda ainda mais.

\section{Referências}

ALVES, G. O que é precariado? São Paulo: Boitempo, 2013. Disponível em: https://blogdaboitempo.com.br/2013/07/22/o-que-e-o-precariado/, acesso em 12/04/2019.

BERRINGER, T. Bloco no poder e as análises de política externa. Revista de Estudos Internacionais (REI), Vol. 6, № 1, p. 5-21, 2015.

BRAGA, R. A política do precariado: do populismo à hegemonia lulista. São Paulo: Boitempo, 2012. 264 p. 
BRANDÃO, M. Cursos superiores de tecnologia: democratização do acesso ao ensino superior? Trabalho Necessário, Ano V, №05, p. 1-15, 2007.

BRASIL. CONSELHO NACIONAL DE EDUCAÇÃO. Parecer CNE/CES no: 277, de 07 de dezembro de 2006. Nova forma de organização da Educação Profissional e Tecnológica de graduação. Brasília (DF): 2006. Disponível em: http://www.cee.pa.gov.br/sites/default/files/pces277_06_0.pdf, acesso em $31 / 10 / 216$.

BRASIL. Decreto № 2.208, de 17 de abril de 1997. Regulamenta o $§ 2$ do art. 36 e os Arts. 39 a 42 da Lei o 9.394, de 20 de dezembro de 1996, que estabelece as diretrizes e bases da educação nacional. Brasília: 17 de abril de 1997. Disponível em: <http://www.planalto.gov.br/ccivil_03/decreto/d2208.htm>, acesso em 02/05/2017.

BRASIL. Decreto № 5.154, de 23 de julho de 2004. Regulamenta o § $2^{\circ}$ do art. 36 e os arts. 39 a 41 da Lei № 9.394, de 20 de dezembro de 1996, que estabelece as diretrizes e bases da educação nacional, e dá outras providências. Brasília: 23 de julho de 2004. Disponível em: <http://www.planalto.gov.br/ccivil_03/_ato20042006/2004/decreto/d5154.htm>, acesso em 02/05/2017.

BRASIL. Lei № 11.892, de 29 de dezembro de 2008. Institui a Rede Federal de Educação Profissional, Científica e Tecnológica, cria os Institutos Federais de Educação, Ciência e Tecnologia, e dá outras providências. Brasília: 2 de dezembro de 2009. Disponível em: <http://www.planalto.gov.br/ccivil_03/_ato20072010/2009/Decreto/D7022.htm>, acesso em 02/05/2017.

BRASIL. Lei no 4.024, de 20 de dezembro de 1961. Fixa as Diretrizes e Bases da Educação Nacional. Brasília (DF): 1961. Disponível em: http://www.planalto.gov.br/ccivil_03/leis/L4024.htm, acesso em 31/10/2016.

BRASIL. Lei № 5.540, de 28 de novembro de 1968. Fixa normas de organização e funcionamento do ensino superior e sua articulação com a escola média, e dá outras providências. Brasília: 28 de novembro de 1968. Disponível em <http://www.planalto.gov.br/ccivil_03/leis/L5540.htm>, acesso em 02/05/2017.

FRANCO, D. S.; FERRAZ, D. L. da S. Uberização do trabalho e acumulação capitalista. Cad. EBAPE.BR [online], vol.17, n.spe, p.844-856, Epub 09-Dez-2019. DOI: https://doi.org/10.1590/1679-395176936.

FRIEDMAN, M. Capitalismo e liberdade. Tradução de Luciana Carli. $2^{\mathrm{a}}$ Ed. São Paulo: Nova Cultural, 1985. 187 p.

GRAMSCI, A. Americanismo e fordismo. São Paulo: Hedra, 2008. 92 p.

GRAMSCI, A. Cadernos do Cárcere - Introdução ao estudo da filosofia. A filosofia de Benedetto Croce. Traduzido por Carlos Nelson Coutinho. Rio de Janeiro: Civilização Brasileira, 1999. Vol. I [494p.] 
GRAMSCI, A. Cadernos do Cárcere - Notas sobre o Estado e a Política. Traduzido por Carlos Nelson Coutinho, Luiz Sérgio Henriques \& Marco Aurélio Nogueira. Rio de Janeiro: Civilização Brasileira, 2000a. Vol. III [428 p.].

GRAMSCI, A. Maquiavel, a política e o Estado moderno. Rio de Janeiro: Civilização Brasileira, 1989. $446 \mathrm{p}$.

INSTITUTO NACIONAL DE ESTUDOS E PESQUISAS EDUCACIONAIS ANÍSIO TEIXEIRA. Sinopse estatística da educação superior 2018. Brasília (DF) INEP, 2019. Disponível em: http://inep.gov.br/sinopses-estatisticas-da-educacao-superior. Acesso em 27/04/2020.

KOSIK, K. Dialética do concreto. Trad. NEVES, Célia; TORÍBIO, Alderico. Rio de Janeiro: Paz e Terra, 2010.

LIMA, J. C.; BRIDI, M. A. Trabalho digital e emprego: a reforma trabalhista e o aprofundamento da precariedade. Cad. CRH, Salvador, v. 32, n. 86, p. 325-342, ago. 2019. DOI: https://doi.org/10.9771/ccrh.v32i86.30561.

MELLO, G. N. de. Cidadania e competitividade: desafios educacionais do terceiro milênio. 10ª Ed. São Paulo: Cortez, 2005. 204 p.

MINISTÉRIO DA EDUCAÇÃO. CONSELHO NACIONAL DE EDUCAÇÃO. Parecer CNE/CES no 436, de 02 de abril de 2001. Assunto: Cursos Superiores de Tecnologia - Formação de Tecnólogos. Brasília (DF), 02 de abril de 2001. Disponível em http://portal.mec.gov.br/cne/arquivos/pdf/CES0436.pdf, acesso em 26/04/2020.

PORTELLI, H. Gramsci e o Bloco Histórico. São Paulo: HUCITEC, 1997.

POULANTZAS, N. Poder político e classes sociais. São Paulo: Editora Martins Fontes, 1977.

SLEE, T. Uberização: a nova onda do trabalho precarizado. Tradutor: PERES, João. São Paulo: Elefante, 2017. 320 p.

SOUZA, J. dos S. Cursos Superiores de Tecnologia. In: SEGENREICH, Stella Cecilia Duarte (Org.). Organização Institucional e Acadêmica na Expansão da Educação Superior: glossário. Rio de Janeiro: Publit, 2016, p. 39-42.

SOUZA, J. dos S.; VEIGA, C. C. P. S. Determinantes sociais e políticos da regulamentação e fomento de cursos superiores de tecnologia no Brasil. Práxis Educacional, v. 16 , n. 38 , p. 461-482, jan. 2020. ISSN 2178-2679. DOI: https://doi.org/10.22481/praxisedu.v16i38.6021.

STANDING, G. The Precariat: the new dangerous class. USA: Bloomsbury, 2011. $198 \mathrm{p}$.

VEIGA, C. C. P. da S. Determinantes sócio-históricos das mudanças recentes na gestão da educação profissional tecnológica no Brasil. Nova lguaçu (RJ); Seropédica (RJ): 2020. 374 Fls. Tese [Doutorado em Educação] - Programa de Pós- 
graduação em Educação, Contextos Contemporâneos e Demandas Populares (PPGEduc), Universidade Federal Rural do Rio de Janeiro (UFRRJ).

VENCO, S. Uberização do trabalho: um fenômeno de tipo novo entre os docentes de São Paulo, Brasil? Cad. Saúde Pública, Rio de Janeiro, v. 35, supl. 1, e00207317, 2019. Epub 30-Maio-2019. DOI: https://doi.org/10.1590/0102-311x00207317. 